\title{
PROPOSAL OF 2D FINITE ELEMENT MODEL FOR SQUARE PILLAR STABILITY ANALYSIS
}

\author{
Nemanja Đokić ${ }^{1}$, Miodrag Duranović ${ }^{1}$, Veljko Lapčević ${ }^{1}$, Slavko Torbica ${ }^{1}$, \\ Milenko Petrović ${ }^{2}$ and Ljubinko Savić ${ }^{2}$
}

Received: November 23, 2018

Accepted: December 20, 2018

\begin{abstract}
It is suggested that 2D finite element method models are used for square pillar stability analysis. Equivalent width of strip pillar that is represented by FE models is determined from tributary area method by introducing equivalence of square and strip pillar loads in tributary area method analysis. With FE analysis it is shown that pillar loads are close to expected, but tributary area method is limited to pillars of small heights and with horizontal deposits. Proposed methodology provides opportunity to model much complex conditions and sequencing of excavation with respect of sequential stress redistribution.
\end{abstract}

Keywords: tributary are method; room and pillar; Finite element method;

\section{INTRODUCTION}

Room and pillar mining assumes that stopes are left open for the whole life of mine and in such case pillars must provide global stability of the mine. Pillar dimensions are affecting both recovery and work safety and as such are sensitive problem in mining.

Ore extraction assumes stress redistribution and further load increase in pillars. In design stage it is important to corelate pillar load with strength of the rock mass that pillar is consisted of.

Widely used method for pillar design is tributary are method Lunder (1994). This method assumes that pillar load comes from weight of the above lying rock mass. This is empirical method that takes into account room spans and pillar width to asses pillar load for the certain depth. This method does not take into account size of the deposit, interaction of adjacent stopes or primary stress state, especially horizontal stresses.

Main conditions that have to be fulfilled for the application of this method is that ore body is huge in its extent, horizontal and at small or medium depth. Beside these there

\footnotetext{
${ }^{1}$ University of Belgrade - Faculty of Mining and Geology

${ }^{2}$ University of Pristina - Faculty of Technical Sciences in Kosovska Mitrovica

Emails: nemanja.djokic@ @rgf.rs; miodrag.duranovic@ rgf.rs; veljko.lapcevic@ rgf.bg.ac.rs; torbica@ rgf.bg.ac.rs; milenko.petrovic@ @r.ac.rs; ljubinko.savic@ pr.ac.rs;
} 
are notable works presented by Maybee (2000), Esterhuizen et al. (2008) and York et al. (2000).

On the other side, 2D Finite element method is widely used numerical method for rock mass simulation. Planar analysis assumes that stopes are infinitely long and therefore it is possible to simulate only striped pillar but no square ones. Herein, procedure on how to create equivalent FEM model for square pillar analysis is presented.

\section{EQUIVALENT 2D FEM MODEL}

Due to the all of disadvantages of tributary are method it is much more convenient to use FEM since its capabilities to take into account different geometries and stress states in the rock mass. However, in order to make representative model for square pillar design it is necessary to find equivalent width of the pillar in FEM model that will represent same situation that is analyzed by Tributary area method.

Herein it is suggested that pillar size in FEM model is adjusted in such manner that pillar load will be close to the load obtained by tributary are method. This would provide a tool for quick and more complex design and analysis of square pillars.

According to the tributary area method square pillar load (Figure 1) is determined as:

$$
\sigma_{p}=\gamma \cdot H_{p} \cdot\left(1+\frac{B}{b}\right)^{2}
$$

Where:

$$
\begin{aligned}
& \sigma p-\text { Pillar load }(\mathrm{MPa}) \\
& \gamma-\text { unit weight of rock mass }\left(\mathrm{MN} / \mathrm{m}^{3}\right) \\
& \mathrm{H} p-\text { depth }(\mathrm{m}) \\
& \mathrm{B}-\operatorname{stope} \operatorname{span}(\mathrm{m}) \\
& \mathrm{B}-\text { pillar width }(\mathrm{m})
\end{aligned}
$$




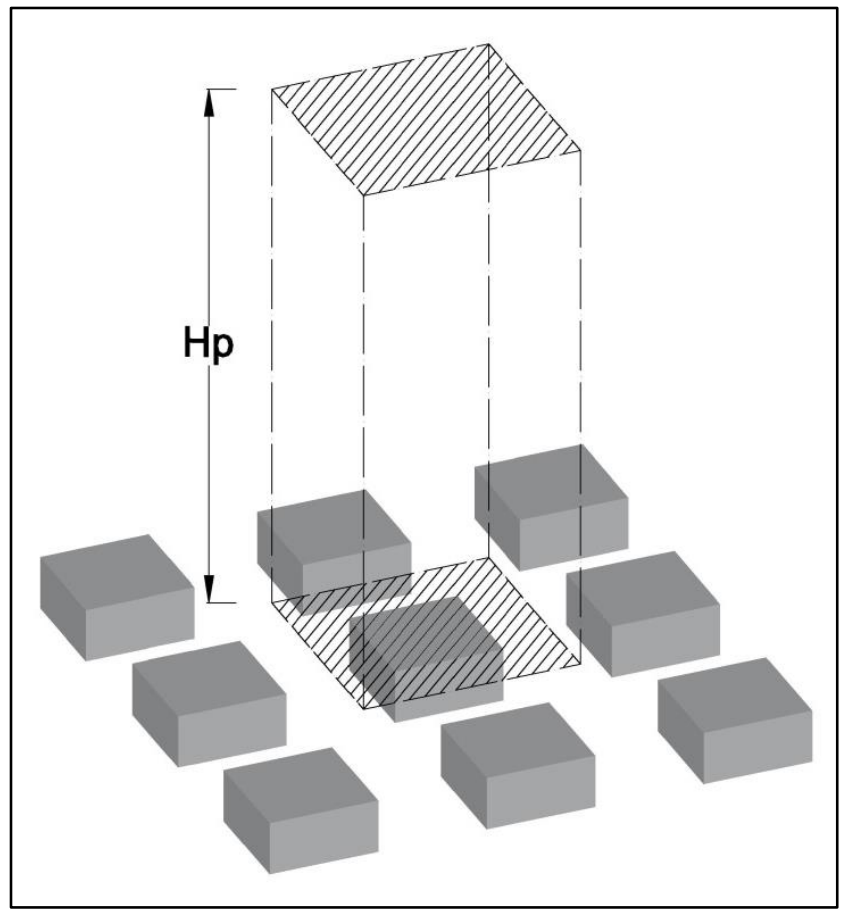

Figure 1 Pillar load prism

As simple illustrative example of room and pillar mining with span and pillar width of $10 \mathrm{~m}$ at depth of $100 \mathrm{~m}$ is given. Weight of rock mass is $0.027 \mathrm{MN} / \mathrm{m}^{3}$, while situation is illustrated in Figure 2.

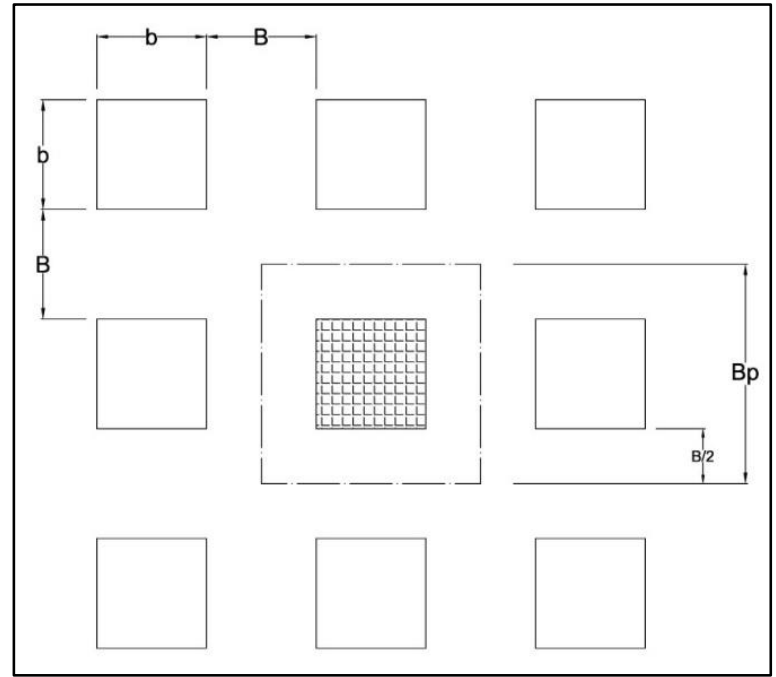

Figure 2 Square pillar layout 
Square pillar load according to equation 1 is:

$$
\sigma p=0,027 \cdot 100 \cdot\left(1+\frac{10}{10}\right)^{2}=10.8 \mathrm{MPa}
$$

In order to prepare equivalent strop pillar model main criteria, that pill load remains same, must be fulfilled. For same width, load of strip pillar will be lower than that in square pillar. This means that in FEM model it is reasonable to decrees pillar width in order to obtain same load.

As critical span, diagonal of the cross is taken as it is illustrated in Figure 3. This is the place where probability of failure is the greatest.

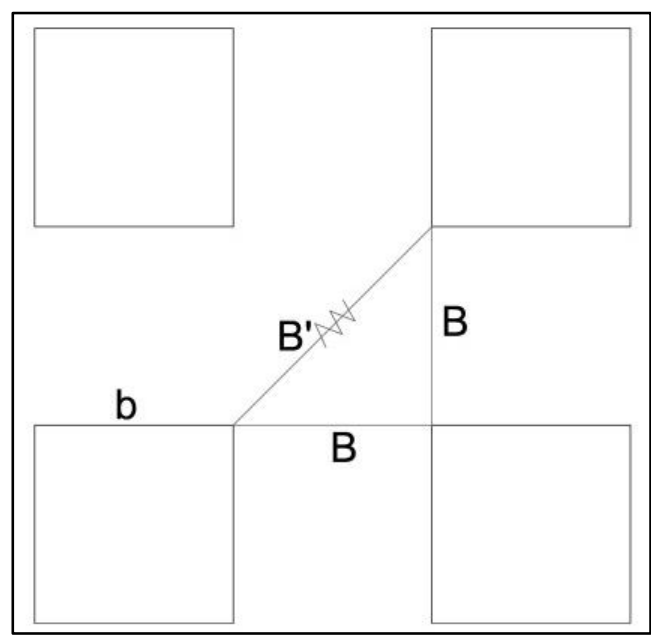

Figure 3 Critical span for pillar design

Diagonal is related to the room span as $\mathrm{B}^{\prime}=\mathrm{B} \sqrt{2}$, and for the given example it is equal to $\mathrm{B}^{\prime}=10 \sqrt{2}=14,1 \mathrm{~m}$.

This diagonal will represent the room span in the FE model. In order to make representative model it is necessary to determine the pillar width using equation based on Tributary area method:

$$
\sigma_{p}=\gamma \cdot H_{p} \cdot\left(1+\frac{B^{\prime}}{b^{\prime}}\right)
$$

Width of equivalent stip pillar is determine from equation 2:

$$
\mathrm{b}^{\prime}=\frac{B^{\prime} \cdot \gamma \cdot H p}{\sigma p-\gamma \cdot H p}, \text { from where } \mathrm{b}^{\prime}=\frac{14,1 \cdot 0,027 \cdot 100}{10,8-0,027 \cdot 100}=4,7 \mathrm{~m}
$$


Figure 4 illustrates equivalent stip pillar layout that will be used in FE analysis.

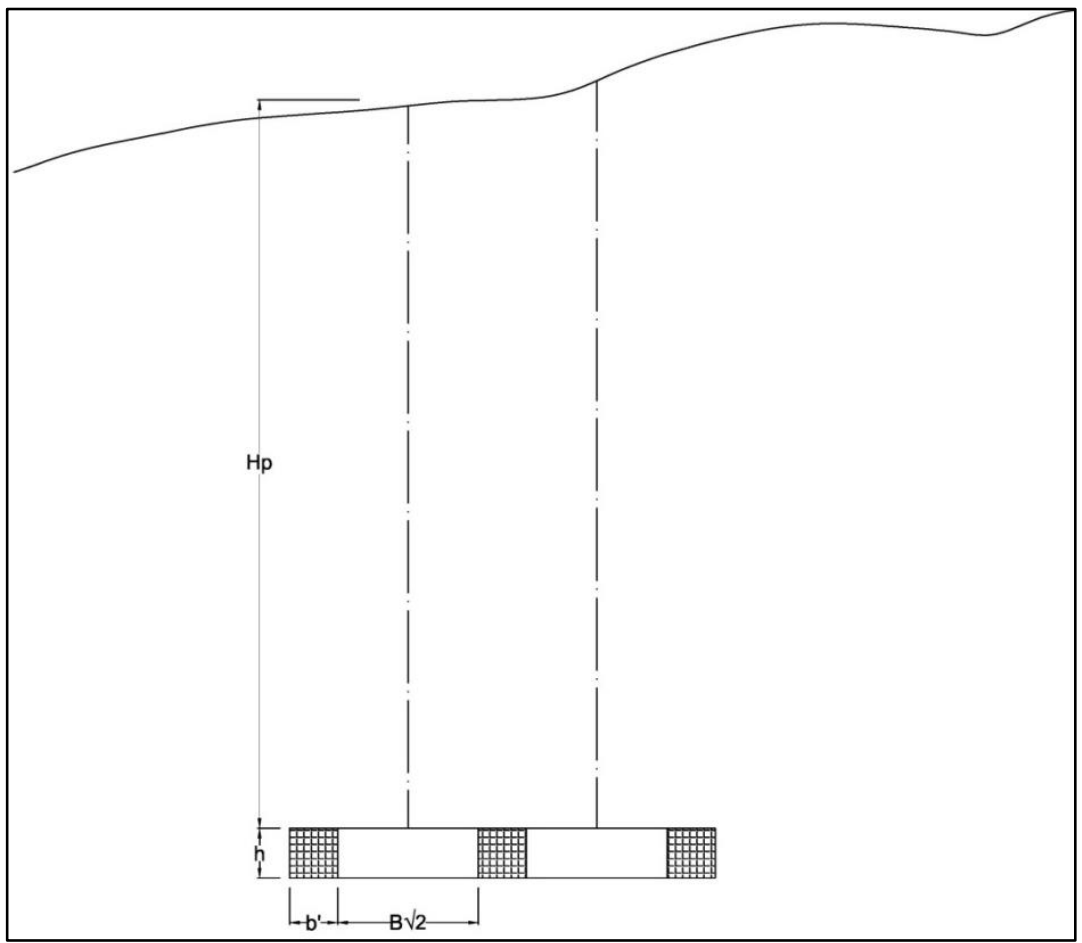

Figure 4 Layout of equivalent strip pillar in planar analysis

New layout presented in Figure 4 is used for FE model where pillar load is analyzed. Main advantage is that more complex mine layout and mining sequence can be simulated, not only single pillar load such as in Tributary method.

\section{FE ANALYSIS}

Using Phase2 (Rocsince Inc.,) FE analysis is undertaken. Model simulates strip pillars with dimensions equivalent to the previously determined by tributary are method. Pillar width is proportionally decreased in order to obtain same pillar load as in square pillars.

Model simulates elastic material in several stages that simulate increasing height of the stope. Hight increment is $5 \mathrm{~m}$. excavation sequence is from the central stopes towards the side. After the first stage where first set of stopes is excavated, pillar load is around $8 \mathrm{MPa}$ (Figure 5). 


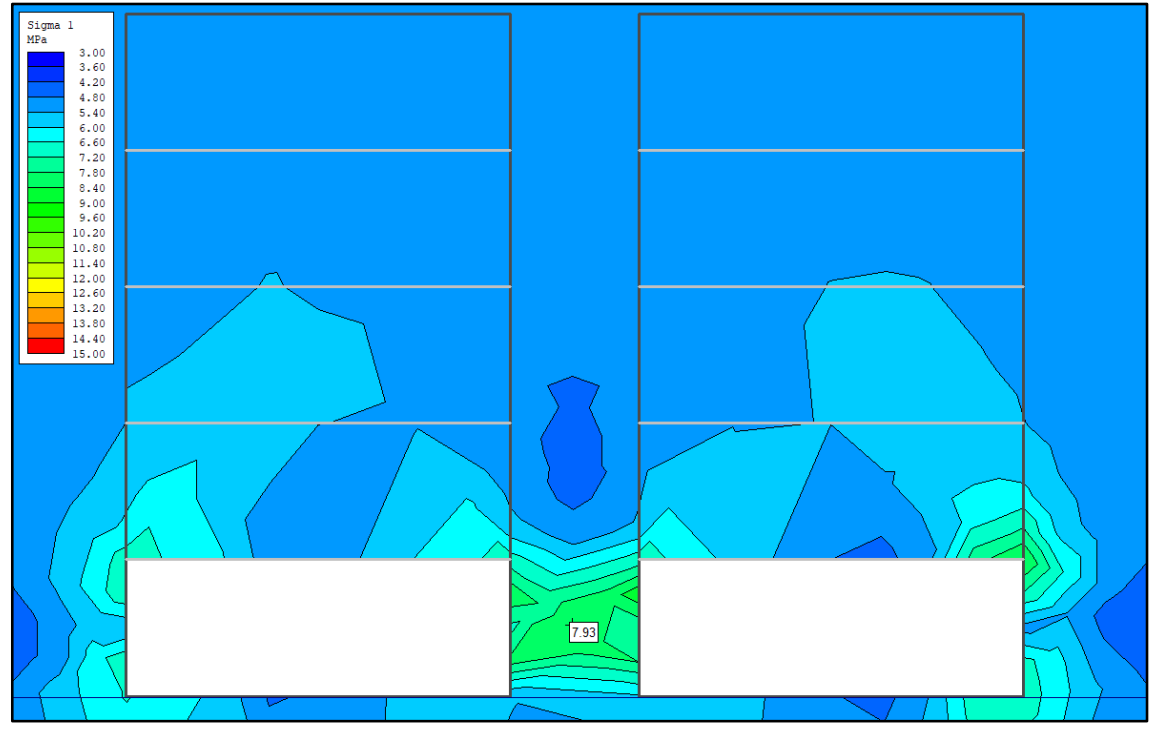

Figure 5 Pillar load after first set of stopes is excavated

By continuing the excavation toward the side stopes, load of the first pillar is increasing to $10.65 \mathrm{MPa}$ which is only $1.5 \%$ different from the load obtained by tributary are method. This situation is illustrated in figure 6 .

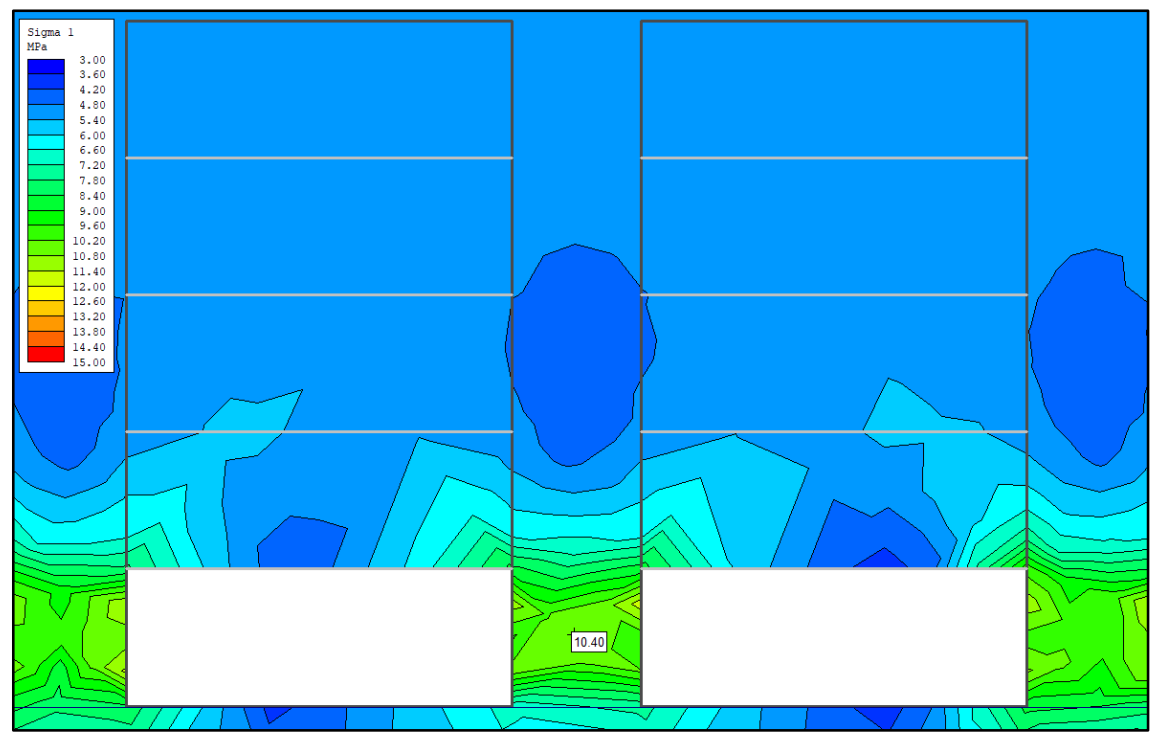

Figure 6 Pillar load after numerous stopes are left open 
Pillar load increase is illustrated in Figure 7. It is shown how load in the central pillar is increasing as excavation continues toward the side stopes. This is situation at the first level and pill height is $5 \mathrm{~m}$.

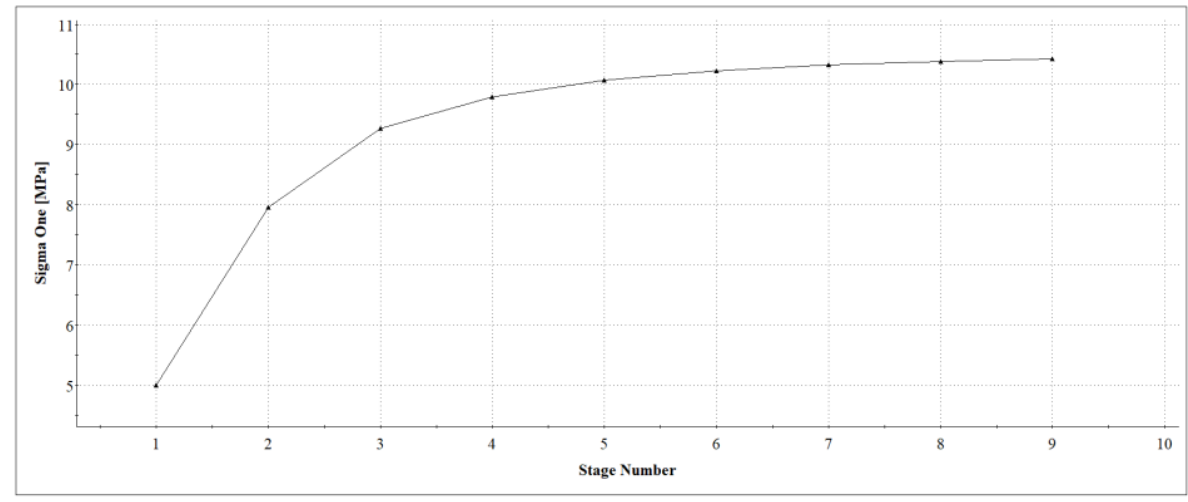

Figure 7 Central pillar load as excavation of first level continues

In further stages of simulation, pillar height is increased by $5 \mathrm{~m}$ in each stage. Final pillar height is $25 \mathrm{~m}$. Figure 8 illustrates load change with increasing height. As it can be seen, major principal stress is decreased around $10 \%$ in final stage. Along with this, minor principal stress is increasing in the pillar side walls.

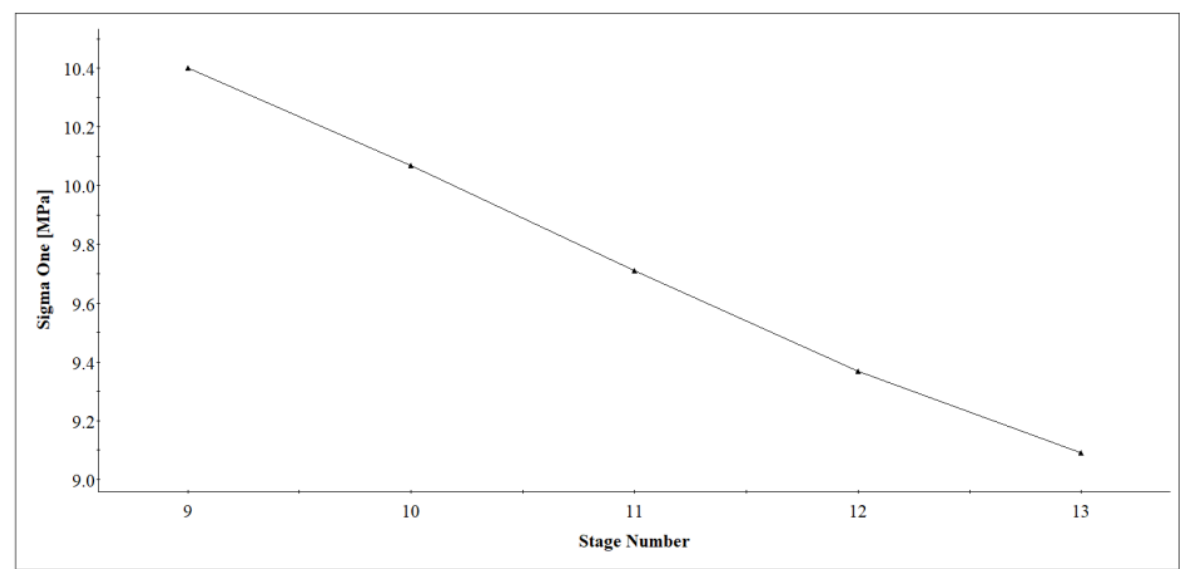

Figure 8 Central pillar load decrease with increasing height

As it can be seen major principal stress is decreasing with increasing height of the pillar. This confirms that tributary area method is useful for pillar with small height . Figures 9-12 illustrate some of the stages of pillar simulation and stress change in different points. 


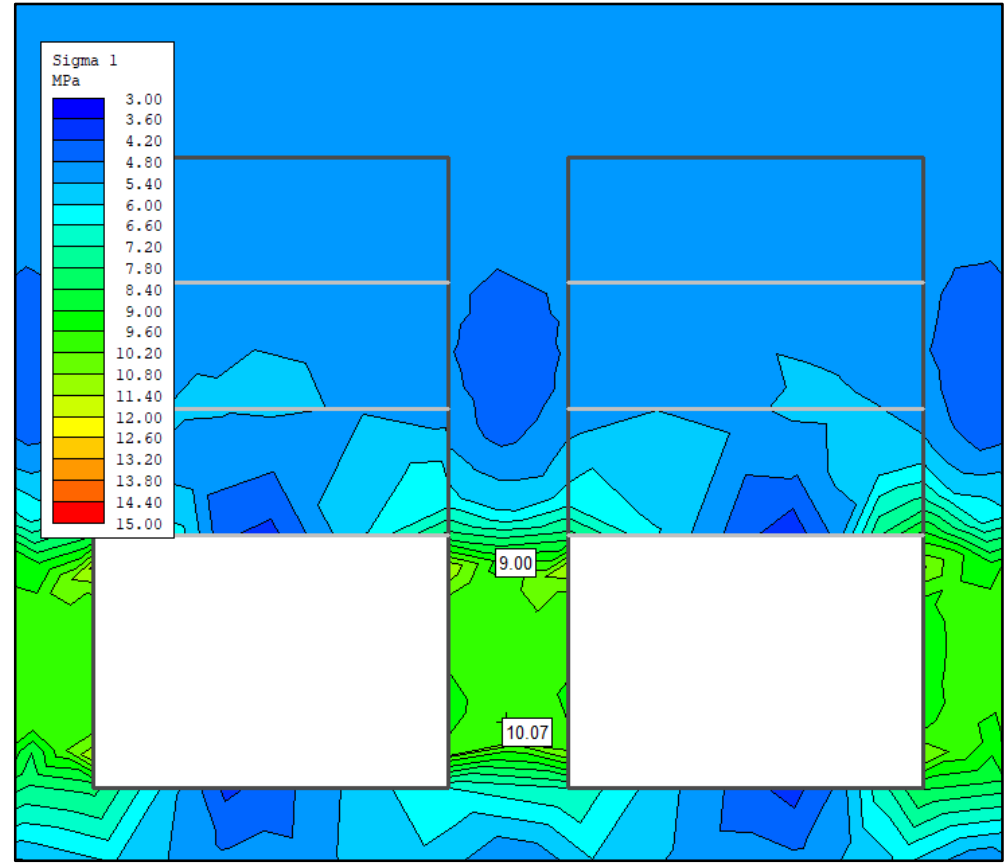

Figure 9 Stress distribution in 10m high pillar

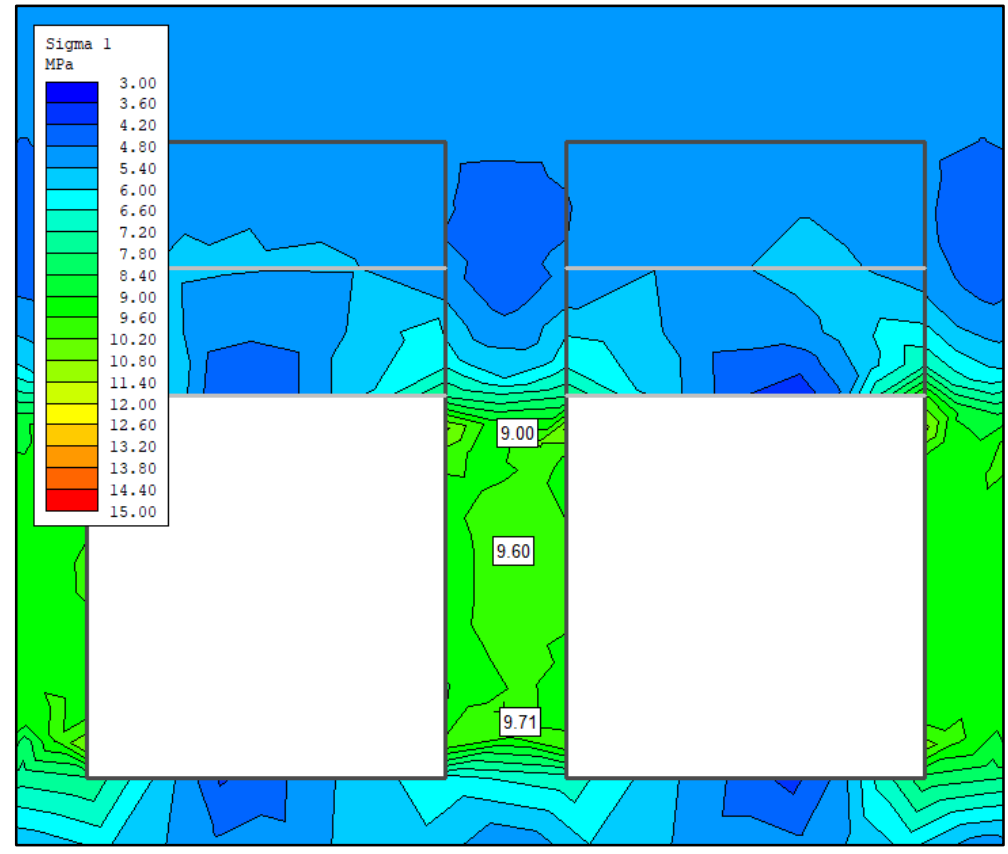

Figure 10 Stress distribution in 15m high pillar 


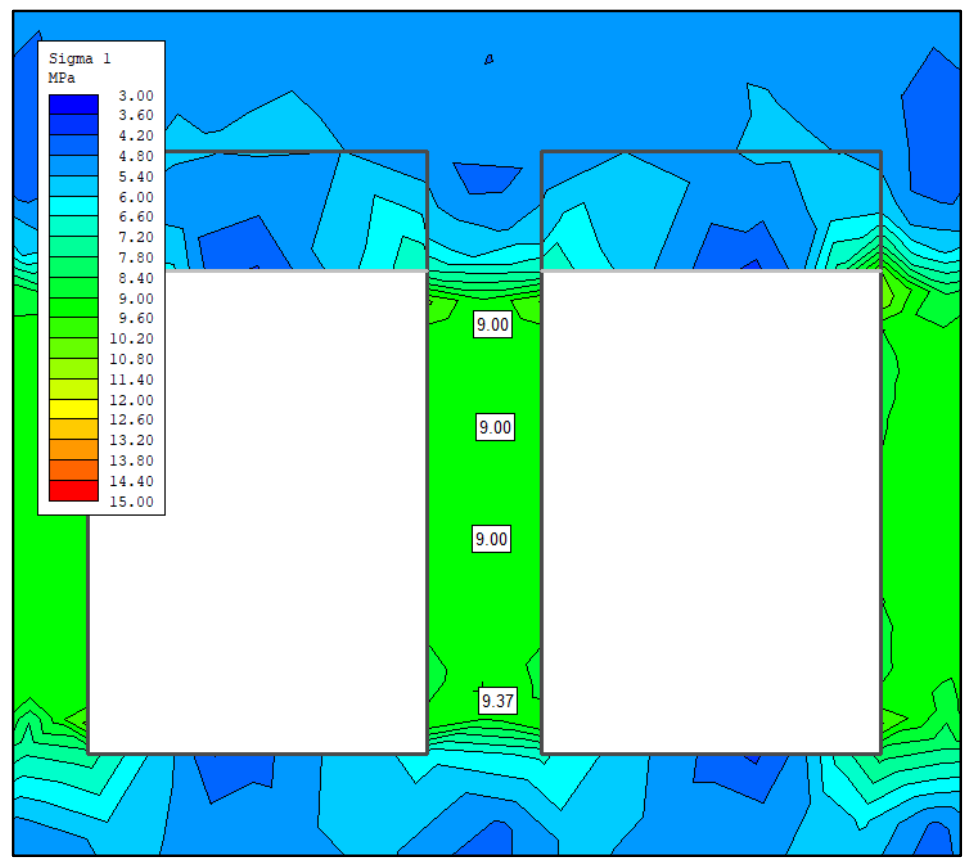

Figure 11 Stress distribution in $20 \mathrm{~m}$ high pillar

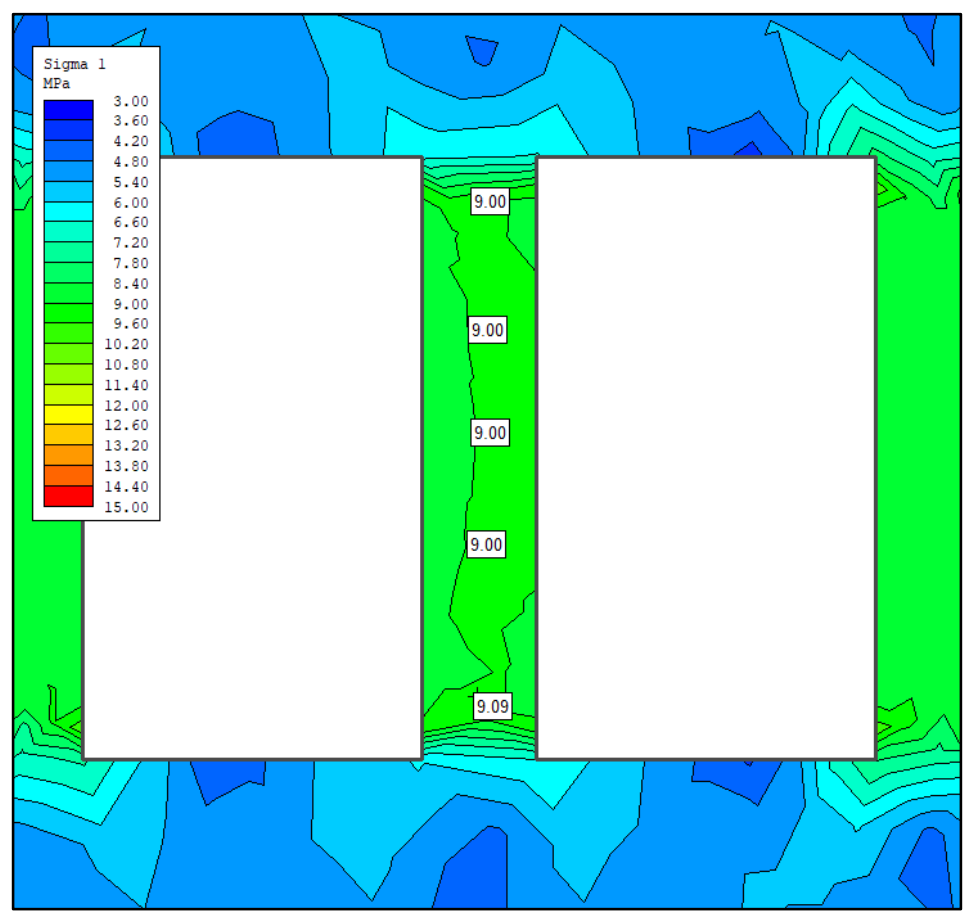

Figure 12 Stress distribution in 25m high pillar 
It is shown that it is possible to create representative 2D FE models to model stability of square pillars. This provides opportunity to model much complex situations and extraction sequence. It is also shown that tributary method is suitable only for the small height pillars, while much more reliable results are obtained by FEM analysis.

\section{CONCLUSION}

This paper presented method for representative modeling of square pillars using 2D FE analysis. As it is known square pillars are commonly designed by 3D numerical method or by empirical approaches. However, it is shown that 2D FE analysis can be used. Main advantage is that is simple in comparison with $3 \mathrm{D}$ numerical models and provides possibility for much more complex problem modeling that empirical tributary area method.

Procedure for determination of equivalent pillar in planar analysis is given. It is shown that pillar load obtained in numerical model is close to load obtained by empirical approach, but it is also shown that tributary area method is confident only with pillars of small heights. In general, presented methodology saves time for model preparation and provides tool for modeling of much more complex conditions than empirical methods.

\section{REFERENCES}

MAYBEE, W.G. (2000) Pillar design in hard brittle rocks. Thesis (MSc), Laurentian University.

ESTERHUIZEN, G.S., DOLINAR, D.R. and ELLENBERGER, J.L. (2008) Pillar strength and design methodology for stone mines. In: Proceedings of the 27th international conference on ground control in mining. Morgantown WV: West Virginia University. pp. 241-253.

YORK, G., CANBULAT, I. and JACK, B.W. (2000) Coal pillar design procedures.

LUNDER, P.J. (1994) Hard rock pillar strength estimation an applied empirical approach. Thesis (PhD) University of British Columbia.

ROCSCIENCE INC. (2011) Phase2 Version 7.0 -Finite Element Analysis for Excavations and Slopes. Toronto, Ontario, Canada. 